\title{
Poultry Shelf-Life Enhancing Potential of Nanofibers and Nanoparticles Containing Porphyra dioica Extracts
}

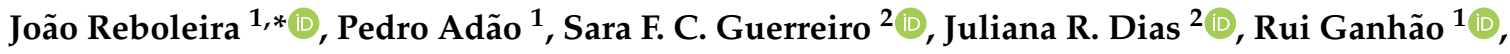 \\ Susana Mendes ${ }^{1}$, Mariana Andrade ${ }^{3}{ }^{-}$, Fernanda Vilarinho ${ }^{3}{ }^{-}$, Ana Sanches-Silva ${ }^{4,5}{ }^{(D}$, \\ Artur Mateus ${ }^{2}$, Nuno Alves ${ }^{2}(\mathbb{D})$ and Susana Bernardino ${ }^{1}$ \\ 1 MARE - Marine and Environmental Sciences Center, ESTM, Politécnico de Leiria, 2520-641 Peniche, \\ Portugal; pedro.adao@ipleiria.pt (P.A.); rganhao@ipleiria.pt (R.G.); susana.mendes@ipleiria.pt (S.M.); \\ susana.bernardino@ipleiria.pt (S.B.) \\ 2 Centre for Rapid and Sustainable Product Development, Politécnico de Leiria, Zona Industrial, \\ Rua de Portugal, 2430-028 Marinha Grande, Portugal; sara.f.guerreiro@ipleiria.pt (S.F.C.G.); \\ juliana.dias@ipleiria.pt (J.R.D.); artur.mateus@ipleiria.pt (A.M.); nuno.alves@ipleiria.pt (N.A.) \\ 3 Department of Food and Nutrition, National Institute of Health Dr Ricardo Jorge (INSA), Avenida Padre \\ Cruz, 1649-016 Lisbon, Portugal; mariana.andrade@insa.min-saude.pt (M.A.); \\ fernanda.vilarinho@insa.min-saude.pt (F.V.) \\ 4 Center for Study in Animal Science (CECA), ICETA, University of Oporto, 4051-401 Oporto, Portugal; \\ anateress@gmail.com \\ 5 National Institute for Agricultural and Veterinary Research (INIAV), 4485-655 Vairão, Vila do Conde, Portugal \\ * Correspondence: joao.reboleira@ipleiria.pt
}

Received: 28 February 2020; Accepted: 24 March 2020; Published: 26 March 2020

check for updates

\begin{abstract}
Aqueous extracts of commercially available red macroalgae Porphyra dioica were integrated as inner coatings of food-grade polypropylene (PP) films through use of electrospinning and electrospraying technologies. Two coating formulations $(\mathrm{A}=5 \mathrm{wt} \%$ P. dioica extract and $7.5 \mathrm{wt} \%$ polyvinyl alcohol (PVA); $\mathrm{B}=1 \mathrm{wt} \%$ P. dioica extract, $1 \mathrm{wt} \% \mathrm{PVA}$, and $17 \%$ gelatine) were evaluated as to their capacity to delay spoilage of minced chicken breasts, through monitoring of microbial growth (total mesophile aerobic colony counts), colour stability, lipid oxidation (thiobarbituric acid reactive substances (TBARS)), and sensory analysis over a 4-day refrigerated storage. Scanning electron microscopy (SEM) imaging revealed an increased nanofiber and nanoparticle density on extract-enriched fibers, without compromise to their morphology or the homogeneity of the coatings. Total microbial counts on coating B samples was significantly $(p<0.001)$ reduced compared to uncoated plastic wraps. The coated samples also exhibited fewer colour degradation, though the coatings did not differ substantially from uncoated plastic wrap. Sensory analysis test subjects successfully distinguished the raw samples based on their treatment and gave a positive approval rating $(66.7 \%)$ to the extract-enriched coatings when asked about edibility post storage.
\end{abstract}

Keywords: electrospinning; electrospraying; porphyra dioica; active packaging; shelf-life

\section{Introduction}

Poultry products are highly susceptible to microbial-induced spoilage. Under refrigeration temperatures and modified atmosphere packaging, raw poultry typically deteriorates in under 10 days after slaughter [1,2]. Common packaging atmospheres in western European markets can have up to $33 \% \mathrm{CO}_{2}$ in their blend, a value that is limited to the flexibility of the packaging material and risk of collapse. However, even under these conditions, poultry shelf-life is relatively short and highly dependent on the state of the initial carcass and stability of storage conditions, among other factors [3,4]. Lipid oxidation is not regarded as a limiting factor for shelf-life in aerobically preserved chilled meat, 
as it occurs at a slower rate than microbial degradation and discoloration. This is not always the case when dealing with modified atmosphere packaged meat, as the other deteriorative effects are suppressed. Poultry, which is richer in polyunsaturated fatty acids, is even more susceptible to lipid oxidation spoilage [5].

Active packaging is a recent technological development that has the potential of extending the shelf-life of meat and poultry. It has been defined as any kind of packaging material that performs a role other than serving as a simple inert barrier to the outside environment, through the direct inclusion of antimicrobial and antioxidant agents into packaging matrix itself [6]. The use of preservative agents in active packaging has a recognized positive influence in the stability of the enclosed food. Application of antioxidant agents, such as nisin, butylated hydroxytoluene (BHT), and butylated hydroxyanisole (BHA) has been thoroughly tested and has reliably increased the shelf-life of food products prone to lipid oxidation [7]. The stability of products susceptible to microbial degradation has, in turn, been successfully enhanced through the use of incorporated antimicrobial agents. Reported examples include carrageenan and grapefruit seed extract composites [8], polylactide electrospun fibers with wild garlic extract [9], and whey protein isolates made into edible coatings enriched with the essential oils of oregano and clove [10]. Cases related to the use of purified or modified natural polymers incorporated into nanofibers meant for direct contact with food products were also reported. Carboxymethylated polysaccharides from dandelions in a $3 \mathrm{wt} \%$ solution, along with $3 \mathrm{wt} \% \mathrm{PEO}$ (polyethylene oxide) were spun into nanofibers and induced significant Listeria monocytogenes growth inhibition [11]. In another recently reported example, a nonspecified phlorotannin was successfully woven into nanofiber coatings along with sodium alginate and PEO. This coating had negligible effect on the sensory quality of the treated chicken meat, and lead to significant reductions in viable Salmonella counts [12].

Despite the volume of work and promising results, the incorporation of antioxidant agents in edible films and packages often relies in the usage of essential oils and other concentrated hydrophobic liquids. These are frequently extracted with highly toxic organic solvents that either constitute a hazard by themselves, or require additional cleaning and purification steps $[13,14]$. In other instances, the agents used in active packaging are the product of chemical manufacture with undesirable environmental impacts [7]. Using green extraction techniques on commonly available natural resources in order to extract the supplementing antioxidant/antimicrobial agents in bioactive films can potentially reduce production costs and create a safer, more sustainable product [15]. In addition, when considering industrial implementation, these extracts greatly benefit from being further purified and thoroughly characterized. The use of crude natural extracts often faces problems when dealing with large scale implementation and reproducibility of results, as these complex mixtures of molecules are prone to seasonal and environmental changes in its sources $[16,17]$.

Some of the most abundant marine resources off the Portuguese coast are the red macroalgae of the Porphyra genus. Porphyra dioica is particularly abundant, and although it has seen use around the world as a food source, it remains grossly underexploited in Portugal, with only recent strides being made in its culture and commerce [18]. These algae are rich in sulphated polysaccharides, particularly porphyran, a sulphated galactan that has so far been loosely described in its structure, but thoroughly detailed in its bioactive abilities $[19,20]$. Zhang et al., 2005, described the polysaccharide isolated from Porphyra capensis as having a linear backbone of alternating 3-linked $\beta$-D-galactose and 4-linked $\alpha$-L-galactose-6-sulfate or 3,6-anhydro- $\alpha$-L-galactose units, along with a ratio of 1.2 to $1 \alpha$-L-galactose-6-sulfate and 3,6-anhydrogalactose [21]. Regarding its in vitro bioactivities, there are extensive reports of antioxidant activity [22,23], and one promising, but yet to be followed up on, antifungal discovery [24]. Antimicrobial potential of algal sulphated polysaccharides remains unexplored, but when obtained from other marine sources, such as fish skin and muscle, they have exhibited potent antimicrobial activities [25,26]. Aqueous solid-liquid extractions followed by ethanol precipitation and separation of said precipitate have previously provided a porphyran-rich extract with confirmed bioactivities [24]. 
Electrospinning is a viable new technique for immobilization of bioactive antioxidants for use in innovative packaging techniques. Electrospun fibres possess high surface-to-volume ratios and can be made from a limitless number of polymeric materials in order to suit a wide array of technological purposes [27-30]. Electrospinning has gained traction over recent years for its ability to produce nanofiber meshes with a small diameter, high surface area, and desirable mechanical properties that are easily manipulated and scalable for mass production. When combined with bioactive agents, these meshes can act as a suitable matrix for their controlled dispersal [12]. The field of food grade electrospun polymers remains open to innovation, but nylon 6,6; PVA (polyvinyl alcohol), PVDF (polyvinylidene difluoride), and PEO have seen wide use in food grade applications. PVA in particular has well documented properties, including high biocompatibility and availability, granting its popular use in food coating and electrospinning research [31,32]. While entirely useable on their own, these synthetic polymers are often paired with other molecules, often biopolymers of natural origin, to achieve more flexibility in electrospinning conditions without compromising biocompatibility. The use of gelatine is widely reported in conjunction with PVA, enhancing the structural properties of the electrospun structures and promoting a controlled released of encapsulated bioactive agents [28,33,34]. It should be mentioned that the dispersal of particles/fibers through electric force is a highly customizable process, and the same equipment that can produce nanofibers can, within the right parameters, coat surfaces through electrospraying. This technique can produce sub-microscale particles that have seen extensive use in novel drug delivery systems, implant coatings, tissue engineering, and other biomedical applications $[35,36]$. Uses in the context of food coatings enriched with natural extracts have also been reported [28,37]. The polymer solutions used to regulate particle size in this process are also compatible with electrospinning, and PVA sees frequent use in both technologies [35,38].

\section{Materials and Methods}

\subsection{Materials}

P. dioica samples were purchased as a dried powder from ALGAplus, Illhavo, Portugal.

Boneless, skin-on chicken breasts were supplied by Lusiaves SA, Portugal. Absolute ethanol was purchased from AGA-Alcool e Generos Alimenticios, Prior-Velho, Portugal. Diatomaceous earth filter aid, peptone water, plate count agar (PCA) media, trichloroacetic acid (TCA), and ethylenediaminetetraacetic acid (EDTA) were purchased from VWR Chemicals, Oud-Heverlee, Belgium. Propyl gallate was purchased from PanReac Química SLU, Barcelona, Spain. Glacial acetic acid was purchased from Scharlau, Barcelona, Spain. Thiobarbituric acid (TBA), 1,1,3,3-tetraetoxypropane (TEP), polyvinyl alcohol PVA ( $>99 \%, 89,000$ to 98,000 g/mol), and gelatine (type A, 300 Bloom, 60 mesh) were purchased from Sigma-Aldrich Chemical Co., St. Louis, MO, USA.

\subsection{Extraction of P. dioica Polysaccharide-Enriched Extract}

The algal polysaccharide extracts were obtained through use of solid-liquid extractions, adapted from methods described in the literature $[19,21,39,40]$. A flowchart of the extraction procedure is presented in Figure 1. All extractions were carried out using water as the extraction solvent, as these extracts proved stable and relatively odourless throughout storage and upon application as nanofibers. Fifty grams of powdered P. dioica were suspended in $1.5 \mathrm{~L}$ of distilled water. The suspension was stirred at $70{ }^{\circ} \mathrm{C}$ for $1 \mathrm{~h}$ and, upon cooling to room temperature, was strained through a piece of synthetic cloth. The obtained liquid was then vacuum filtered through a diatomaceous earth pad and then evaporated in a rotary evaporator $\left(60^{\circ} \mathrm{C}\right)$ until a viscous amber residue was obtained. The residue was treated with ca. $500 \mathrm{~mL}$ of absolute ethanol (99.9\%) by immersion and vigorous shaking. The resulting suspension was allowed to settle, and the supernatant liquid was carefully decanted, after which, $250 \mathrm{~mL}$ of ethanol were added to the suspension. The slurry was transferred into a kitchen blender and was mixed thoroughly before being vacuum filtered with quantitative filter paper (Filter-Lab nr 2240) and rinsed thoroughly with absolute ethanol. The retained solids were recovered and then dried 
at $50{ }^{\circ} \mathrm{C}$ over the course of five days in a convection oven. This process resulted in a light brown solid extract with a slight seafood-like aroma. Extraction yields using this method were approximately $6 \%$.

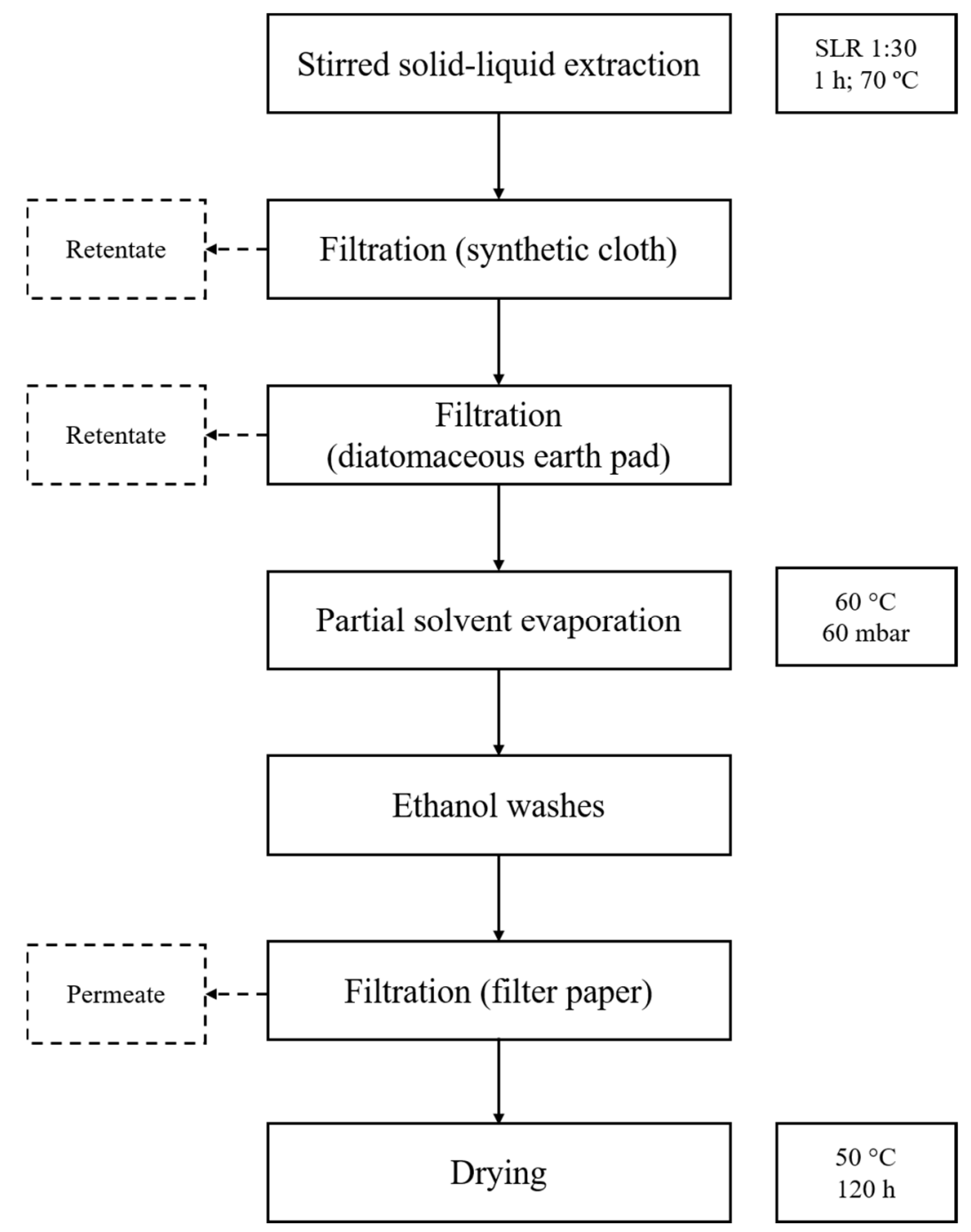

Figure 1. Flowchart of the extraction process used for obtaining aqueous $P$. dioica extracts. Dashed lines represent the rejected fractions of filtration.

The dried extract was analyzed using a Fourier transform infrared (FTIR) spectroscopy with attenuated total reflectance (ATR), confirming the presence of porphyran, as per displayed in Figure 2. (See Figure S1 in the Supporting Material for the full spectrum). FTIR analyses were carried out using an Alpha-P Brucker FTIR-ATR spectrometer, in the range of $4000-400 \mathrm{~cm}^{-1}$, at a $4 \mathrm{~cm}^{-1}$ resolution with 64 scans. It was possible to observe the absorption bands typically assigned to the sulphate ester moieties at ca. 1245 and $813 \mathrm{~cm}^{-1}$. The strong bands within the $1200-1000 \mathrm{~cm}^{-1}$ range were tentatively assigned to secondary alcohol C-O stretching vibrations and galactose residue ring vibrations, as reported for closely related galactans such as carrageenan and agarose [41,42]. The existence of a weak band at ca. $932 \mathrm{~cm}^{-1}$ was attributed to the presence of 3,6-anhydrogalactose residues in the polysaccharide chain. Additional bands could be observed at ca. 3360 and $1652 \mathrm{~cm}^{-1}$, which were respectively assigned to hydroxyl and carbonyl stretching vibrations. The $\mathrm{C}-\mathrm{H}$ stretching vibrations were also observed as weak bands in the $3000-2800 \mathrm{~cm}^{-1}$ range $[21,39,40]$. 


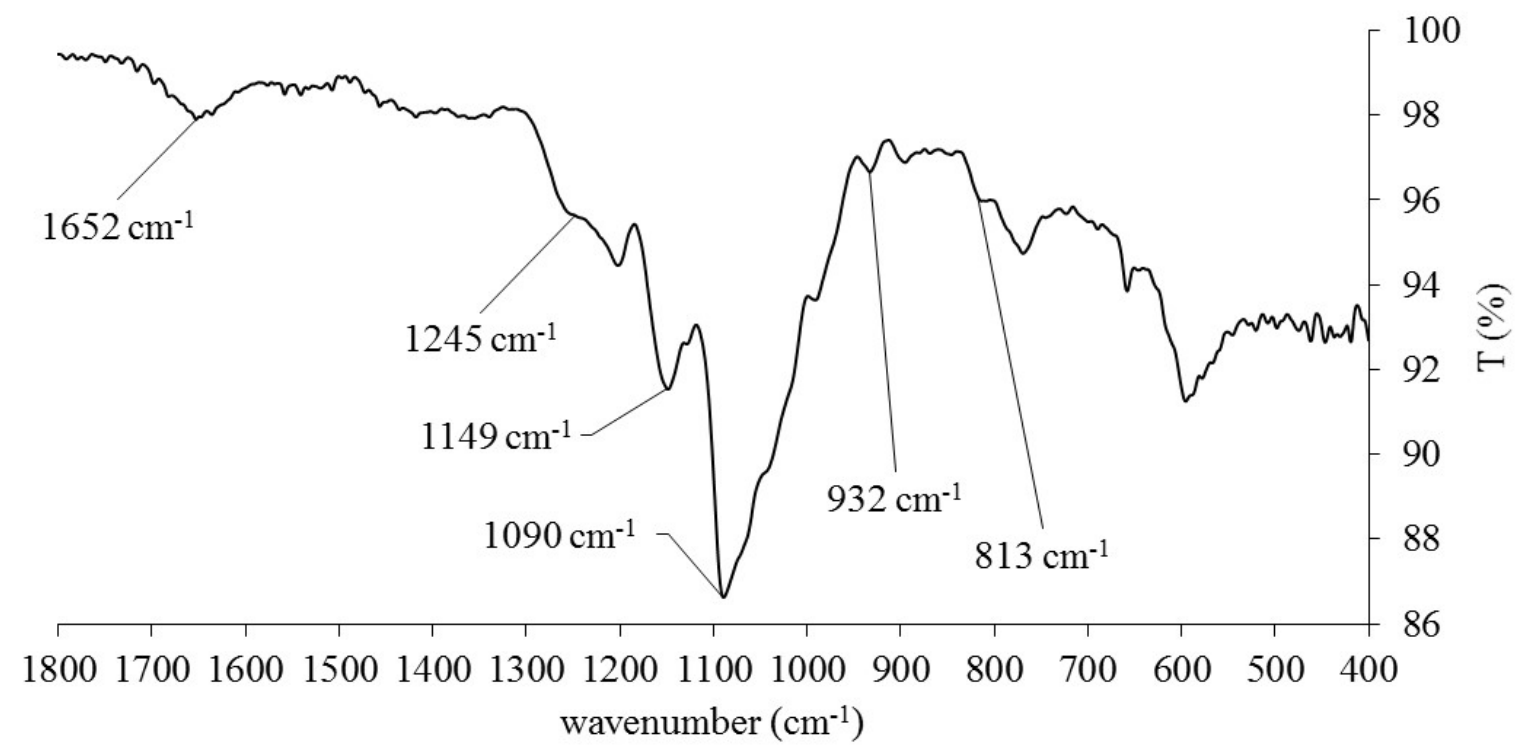

Figure 2. Close-up of the ATR-FTIR spectrum of the solid porphyran-enriched extract.

\subsection{Electrospinning Technique}

All coatings subsequently discussed were produced using a variable voltage, lab-built electrospinning apparatus. Feed solutions were introduced through a $2.5 \mathrm{~mL}$ plastic syringe, connected to a gauge 22 stainless steel needle. The spun material was collected in PP (polypropylene) sheets, which was covered the 10 by $10 \mathrm{~cm}$ copper collector. Flow rates were kept at $0.1 \mathrm{~mL} / \mathrm{h}$, as higher flows consistently lead to uneven coatings on the current setup. Experiments were carried out at room temperature $\left(21^{\circ} \mathrm{C}\right)$ with $45 \%$ humidity.

From these base conditions, two distinct coating formulations were tested, with slight operational adjustments that guaranteed even distribution of the spun material. Coating A was made from an aqueous solution of $5 \mathrm{wt} \%$ P. dioica extract and $7.5 \mathrm{wt} \%$ polyvinyl alcohol (PVA), spun under $10.5 \mathrm{kV}$ of tension, and with a $12 \mathrm{~cm}$ needle tip to collector distance. Coating $\mathrm{B}$ was fabricated from an aqueous solution of $1 \mathrm{wt} \%$ P. dioica extract, $1 \mathrm{wt} \% \mathrm{PVA}$, and $17 \mathrm{wt} \%$ gelatine, spun under $16.5 \mathrm{kV}$ of tension, with a $15 \mathrm{~cm}$ needle tip to collector distance. Thirty-six individual 15 by $15 \mathrm{~cm}$ sheets of each film formulation were produced, guaranteeing three identically coated samples for each assay and instance of sampling. Extract concentrations employed were the highest that could be managed without compromising the production of a homogenous coating, with the use of more P. dioica extract resulting in fibre clumping or abundant and oversized droplets.

The general morphology of the coated films was observed with SEM, using a Vega3 Tescan (Tescan, Czechia), with $15 \mathrm{kV}$ of voltage and a working distance ranging from 15.80 to $15.87 \mathrm{~mm}$. Prior to examination samples were coated with a gold/palladium $(\mathrm{Au} / \mathrm{Pd})$ thin film, by sputtering, using the sputter coater equipment (Quorum Technologies).

\subsection{Shelf-Life Parameter Analysis}

\subsubsection{Poultry Sample Coating and Storage}

The boneless, skin-on chicken breasts used for testing the shelf-life enhancing effect of the coated films were received in refrigerated plastic trays and processed within $12 \mathrm{~h}$ of slaughter. The trays were opened, and the chicken breasts were ground into round paddies ( $55 \mathrm{~mm}$ wide, $15 \mathrm{~mm}$ thick) using a sanitized food processor inside a laminar flow chamber. These paddies were then manually wrapped in the coated PP film sheets and stored inside $90 \mathrm{~mm}$ petri dishes for convenience. "No film" (NF) control samples were stored inside the petri dishes without wrapping of any kind, while "uncoated film" (UF) control samples were wrapped in uncoated PP film. The samples were stored for a maximum period 
of four days under $4{ }^{\circ} \mathrm{C}$, and while in storage, the petri dishes were lightly pressed, as to guarantee the paddies inside were making full contact with the coated wrapping. Figure 3a shows the wrapped chicken paddy inside its storage petri dish. Figure $3 \mathrm{~b}$ demonstrates how these samples were stored in refrigeration.

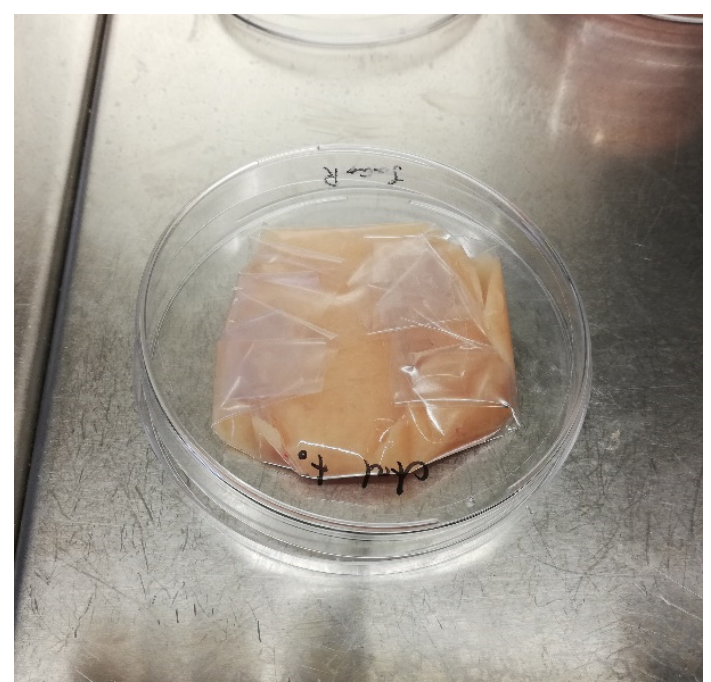

(a)

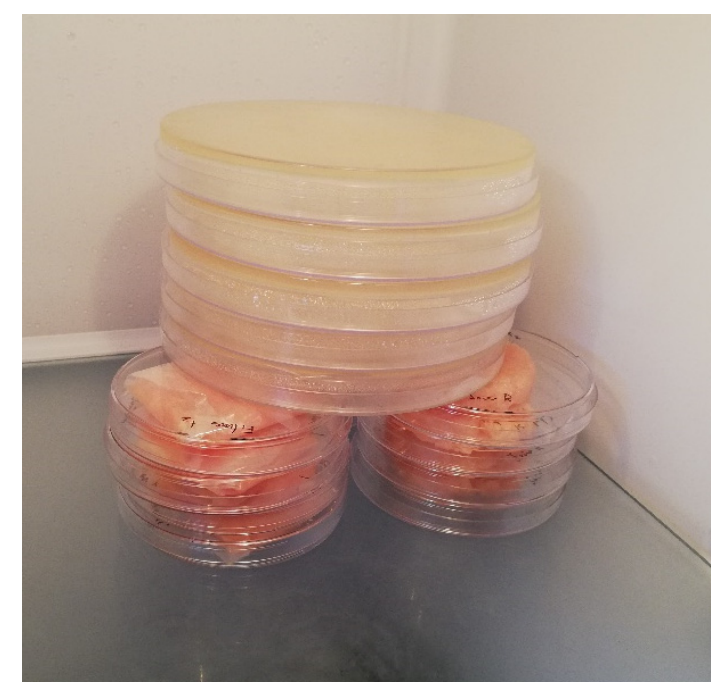

(b)

Figure 3. (a) Manual wrapping of the chicken breast paddies with electrospin-coated polypropylene (PP) film. (b) Storage of a small batch of samples for microbiological assay, with PP wrapped paddies on the left, and control (not wrapped) on the right.

\subsubsection{Microbiological Counts of Spoilage Organisms}

The microbiological conformity of the coated poultry was tested with total aerobic plate counts, closely following the procedures of ISO 4833-1:2013. Samples were tested at 0, 48, and $96 \mathrm{~h}$ post-wrapping, with $0 \mathrm{~h}$ samples simply being uniformly pressed against the coat wrapping and immediately analyzed. Samples were serially diluted in peptone water and pour plated in PCA, followed by a 3-day incubation at $30^{\circ} \mathrm{C}$. The total number of viable colonies was counted after the incubation was complete, and results were expressed in colony forming units (CFU/g of sample). Limitations on electrospinning output and supply of poultry meat samples lead to both coating formulations being tested in separate days, with different batches of packaged chicken breasts tested on each day.

\subsubsection{Evaluation of Colour Stability and Lipid Oxidation}

The potential effect of the electrospun coatings on shelf-life parameters related to oxidation phenomena was evaluated by measuring colour stability and the thiobarbituric acid reactive substances (TBARS) assay. Colour stability was quantified as the colour difference $\left(\Delta E^{*}\right)$ measurable with a Chroma meter (Minolta, CR-400, Tokyo, Japan) in the CIELAB colour space. The equipment was calibrated with a single standard $\left(\mathrm{L}^{*}=97.75, \mathrm{a}^{*}=-0.49\right.$, and $\left.\mathrm{b}^{*}=1.96\right)$ white colour plate. Changes in colour against the initial $(\mathrm{t} 0)$ sample were calculated using the simplified CIE76 (International Commission on Illumination, Germany, 1976) represented below:

$$
\Delta E_{a, b}^{*}=\sqrt{\left(L_{2}^{*}-L_{1}^{*}\right)^{2}+\left(a_{2}^{*}-a_{1}^{*}\right)^{2}+\left(b_{2}^{*}-b_{1}^{*}\right)^{2}}
$$

where $\mathrm{L}_{1}, \mathrm{~L}_{1}$, and $\mathrm{L}_{1}$ are the colour coordinates for the tested sample at the beginning of storage, and $\mathrm{L}_{1}, \mathrm{~L}_{1}$, and $\mathrm{L}_{1}$ are the readings for that same sample at the time of testing. The values treated were the 
result of three readings along separate locations of the raw poultry paddies, after they were processed and stored as described in the previous step for microbiological counts.

The TBARS assay used for the evaluation of lipid oxidation was based on the methodology of Lemon, 1975. Five grams aliquots of raw chicken paddy were extracted using a $7.5 \mathrm{wt} \% \mathrm{TCA}$ solution with $0.1 \mathrm{wt} \%$ EDTA and $0.1 \mathrm{wt} \%$ propyl gallate. Extraction occurred under heavy stirring for $5 \mathrm{~min}$. The resulting slurry was vacuum filtered through a Whatman No. 4 filter paper (Maidstone, UK) and the filtrate was transferred to screw cap glass test tubes. Five millilitres of a $20 \mathrm{mM}$ solution of TBA was added to the tubes which were then incubated on a boiling water bath for $40 \mathrm{~min}$. After cooling, the absorbance at $530 \mathrm{~nm}$ was read for each sample, and compared to a TEP standard curve. Three replicas of each treatment were used for both colour stability and lipid oxidation assays.

\subsubsection{Sensory Analysis}

The sensory impact of the 4-day treatment with electrospun coating B $(1 \mathrm{wt} \%$ P. dioica extract, $1 \mathrm{wt} \%$ PVA, $17 \mathrm{wt} \%$ gelatine) was evaluated with a Triangle Test, as detailed in the published work of Civille, Carr, and Meilgaard, 2015 [43]. Cubic slices of approximately $1.5 \mathrm{~cm}$ width of the processed and stored chicken breasts were enclosed in $50 \mathrm{~mL}$ plastic centrifuge tubes and given a random three number code for identification. Test subjects were supplied with three combinations of the three samples (coated film, film, no film), two of which were identical, with the goal of identifying the odd one. Distinction was only allowed through the sense of smell and touch, with clear indication of the inedible nature of the raw samples. Considering the spoiling that some of the samples demonstrated, nitrile rubber gloves and tweezers were supplied to facilitate handling. Additionally, the subjects were inquired about their opinion on whether or not the supplied samples seemed fit for consumption, with a yes or no answer.

The panellists consisted of 12 untrained volunteers, not associated with the present work, and all of them researchers or doctorate students working in MARE-Politécnico de Leiria at the time the trials took place. Ages ranged from 24 to 51 years, with nine of the twelve panellists being female.

\subsection{Statistical Analysis}

All experiments were performed with at least three replicas and are presented as mean \pm standard deviation. Analysis of variance were performed in Statistica v12, with a $p$-value below 0.05 considered significant. Graphical display of results was performed in GraphPad Prism v6.01.

\section{Results and Discussion}

\subsection{Results of Electrospinning Technique}

Figure 4 shows the surface morphology of the electrospun coatings imaged using SEM. The images show that the presence of gelatine was essential for the development of nanofibers while using the current electrospinning setup, as these structures were absent in the formulation without it. Instead, a process resembling electrospraying happened in coating A (with and without extract), with clearly identifiable microdroplets of the coating solution evenly spread along the PP sheet. Considering that the process of electrospraying is capable of producing uniform layers of coating material and has successfully been used in active packaging in multiple occasions, these coatings were cleared for further testing on shelf-life determining assays. It is also noticeable that the P. dioica extract had a seemingly positive effect on the particle density of the electrosprayed coatings, as well as allowing the formation of larger sized droplets. While evenly sized droplets are often desired in electrospraying, the difference in size between these seems to be close to what author Kim et al., defined as acceptable in his 2015 publication. 


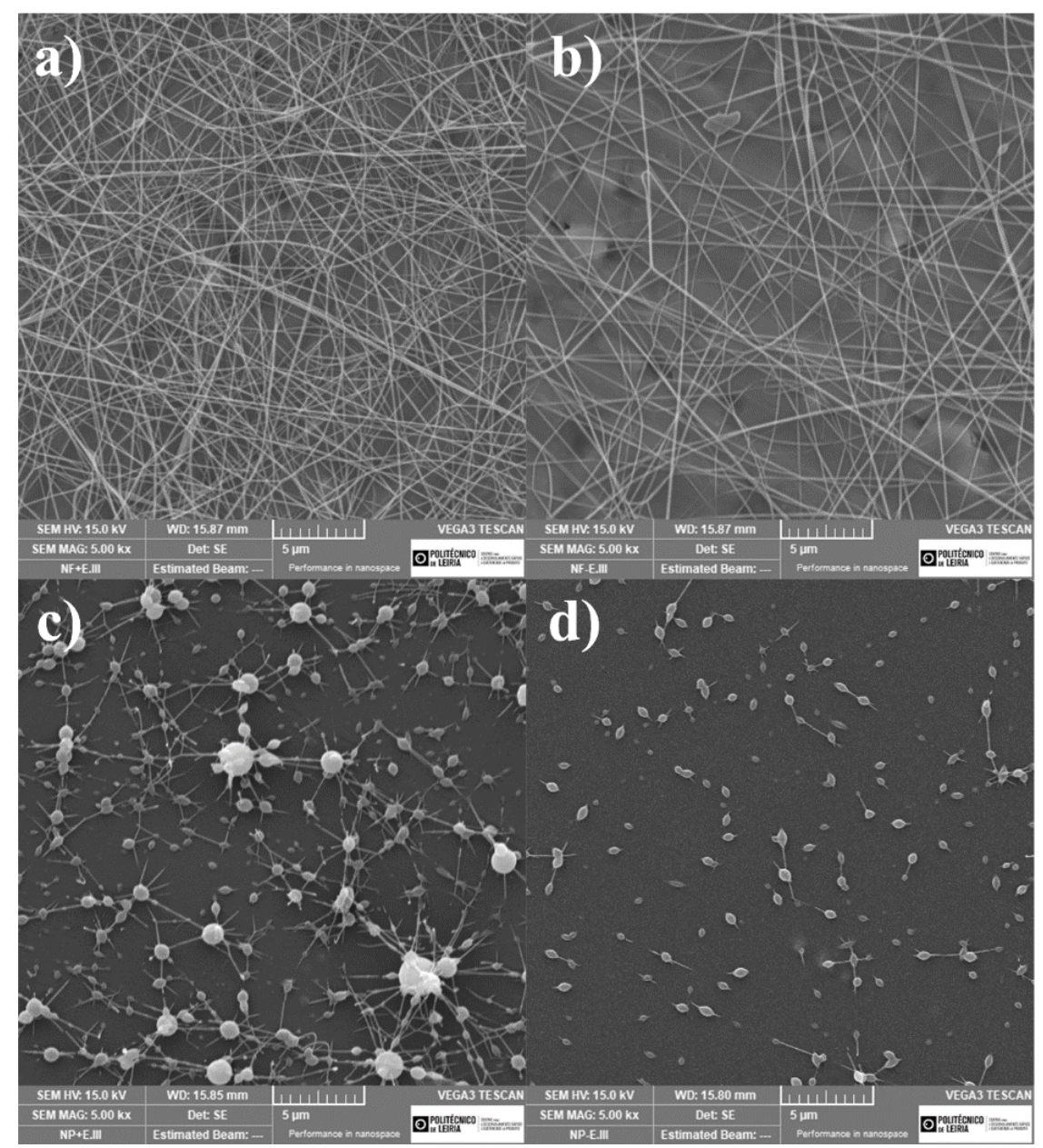

Figure 4. SEM images of the surface of (a) coating B (1 wt $\%$ P. dioica extract, $1 \mathrm{wt} \% \mathrm{PVA}, 17 \mathrm{wt} \%$ gelatine), (b) coating B without extract ( $1 \mathrm{wt} \%$ PVA, $17 \mathrm{wt} \%$ gelatine), (c) coating A (5 wt $\%$ P. dioica extract and $7.5 \mathrm{wt} \%$ PVA), (d) coating A without extract (7.5 wt \% PVA). All images were captured at 5000x amplification.

The images also showed the successful weaving of nanofibers in coating B, reaffirming the use of gelatine as crucial for this end. Average fibre width was measured at $179 \pm 65 \mathrm{~nm}$ for coating $B$ without extract, and $205 \pm 46 \mathrm{~nm}$ for coating B with extract, with an estimated target thickness of 100 to $200 \mu \mathrm{m}$ for all coated surfaces. Similarly to what happened in coating A, the presence of $P$. dioica extract caused a higher density of fibrous structures to accumulate on the receiver during the same length of time.

\subsection{Shelf-Life Parameter Analysis}

\subsubsection{Microbiological Counts of Spoilage Organisms}

Figure 5 displays the total number of mesophile aerobic spoilage organisms counted for the poultry samples subjected to incubation with and without film coatings. 

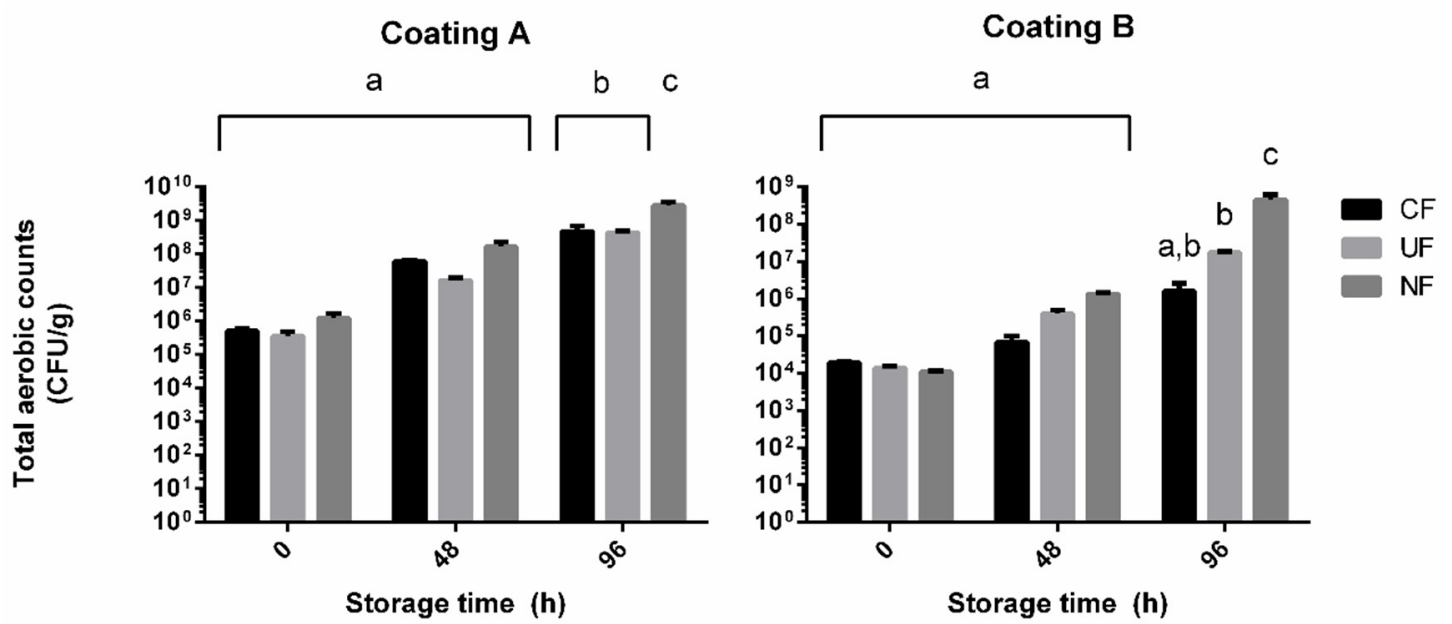

Figure 5. Total mesophile aerobic organisms counts during storage of poultry samples wrapped in coated PP films (CF), uncoated PP films (UF), and no film (NF). Coating A = $5 \mathrm{wt} \%$ P. dioica extract and $7.5 \mathrm{wt} \%$ PVA. Coating $\mathrm{B}=1 \mathrm{wt} \%$ P. dioica extract, $1 \mathrm{wt} \% \mathrm{PVA}$, and $17 \mathrm{wt} \%$ gelatine. Results are presented as averages $(n=4)$ and standard deviation. a, b, and c represent statistically identical counts with $p<0.001$, determined by Tukey's HSD.

The results show a noticeable decrease on microbial load in all samples processed by film wrapping, regardless of the presence of inner electrospun/sprayed coating. This difference was indeed inexistent after $96 \mathrm{~h}$ of storage in the samples treated with coating A (coating A sample: $8.69 \pm 0.24 \log \mathrm{CFU} / \mathrm{g}$, PP coated sample: $8.65 \pm 0.05 \log$ CFU/g, uncoated sample: $9.44 \pm 0.11 \log$ CFU/g). The reduced counts observed on both these treatments can most likely be attributed to the barrier effect of the PP film, as the tight packaging of the poultry paddies left minimal headspace for aerobic growth. The difference in treatments is, however, noticeable in the assay involving the use of coating $\mathrm{B}$, as this proved to be more effective at lowering microbial counts than the uncoated PP film (coating B sample: $6.17 \pm 0.33 \log$ CFU/g, PP coated sample: $7.22 \pm 0.03 \log$ CFU/g, uncoated sample: 8.62 $\pm 0.16 \log \mathrm{CFU} / \mathrm{g}$ ). These reductions, while not as accentuated as others reported in antimicrobial natural substance-enhanced nanofibers, are still above two log cycles for coating B [11,12]. The results would suggest unremarkable potential present in P. dioica extracts since coating $\mathrm{A}$, having a higher concentration of algal extract, presented little to no benefit compared to the uncoated control film. Not considered in this conclusion are the morphological differences between the two coatings, with the nanofibers of coating B possibly presenting a much higher surface area. This could increase the exposure the poultry product had to the active agent and contribute more than the extract concentration itself to the inhibition of microbial growth. These results raise the question of what would happen to microbial growth on samples coated with a solution similar to formulation B, but higher P. dioica extract concentrations. It is expected that such formulation would result in an even higher growth inhibition and a more valuable coating formulation, given the higher concentration of active agent. It has been mentioned in our methodology section that $P$. dioica concentrations above $1 \mathrm{wt} \%$ resulted in irregular coating matrixes in all tested conditions. Further experimenting with electrospinning settings and coating formulations will continue and will be aimed towards incorporating higher natural extract concentrations. Regardless of treatment, all samples reached the end of the incubation period with counts greater than $10^{5} \mathrm{CFU} / \mathrm{g}$, which are deemed unfit for sale in European Commission Regulation (EC) No. 1441/2007. This is not to be used as an indicator of ineffective treatment, as the handling of the chicken breasts can impart microbial load, even with proper precautions. Different batches of the supplied poultry have also proven to have very different initial microbial populations, as can be seen by comparing the results of samples not subjected to incubation $(\mathrm{t} 0)$ between the two assays. 


\subsubsection{Evaluation of Colour Stability and Lipid Oxidation}

Figure 6 details the results of the colour stability assays performed on the raw poultry paddies after 48 and $96 \mathrm{~h}$ of refrigerated storage. The results demonstrate no significant effect of the application of electrospun/sprayed coating on colour stability, with the only noticeable differences occurring on the exposed control samples. A slight reduction of colour degradation seemed to occur on coated samples, but without statistical significance. This leads to believe that the minimal headspace left by the wrapping of PP films is the main deterrent to the development of oxidation products, and an effective barrier to oxidative damage in poultry when tightly packed.

\section{Coating A}

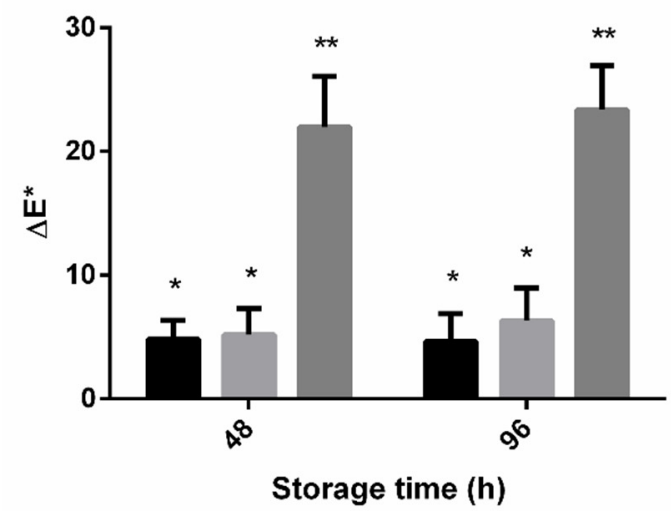

\section{Coating B}

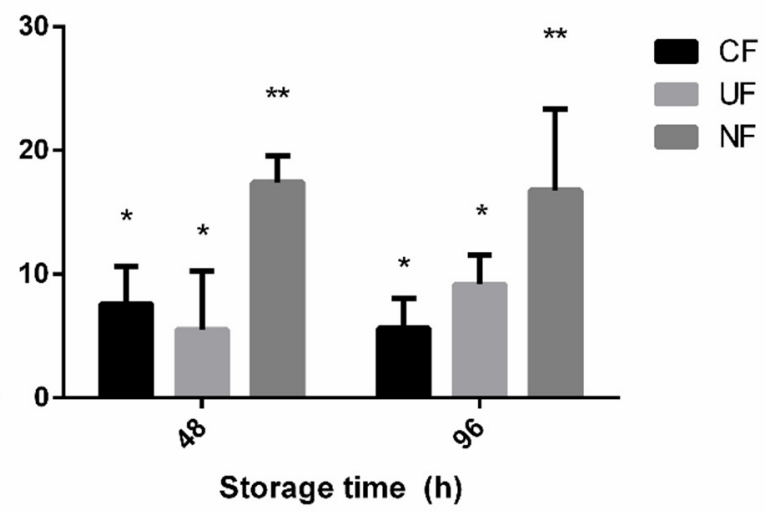

Figure 6. Colour difference between poultry samples treated with (CF) coated PP film, (UF) uncoated PP film, (NF) no film. Coating $\mathrm{A}=5 \mathrm{wt} \% \mathrm{P}$. dioica extract and $7.5 \mathrm{wt} \% \mathrm{PVA}$. Coating $\mathrm{B}=1 \mathrm{wt} \%$ P. dioica extract, $1 \mathrm{wt} \% \mathrm{PVA}$, and $17 \mathrm{wt} \%$ gelatine. Results presented as the average of three readings of three samples $(n=3)$. ${ }^{*}$ and ${ }^{* *}$ Identify statistically identical results, with $p<0,01$, determined by Tukey's HSD.

Figure 7 represents the results from the TBARS assay. With no statistical differences between the tested conditions, this test did not lead to conclusive evidence regarding the antioxidant ability of $P$. dioica extract-enriched coatings on poultry meat. It is likely that the choice of poultry tissue used in this assay, it being skin on chicken breast ground into a paddy, is not suited to display antioxidant activities due to overall low fat content. Further testing of these coatings still needs to evaluate their effect on oxidative degradation and should be performed on darker and fatter meats.

Coating A

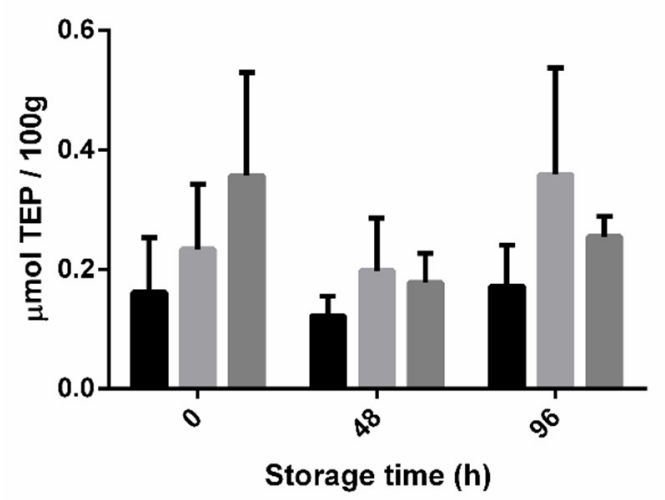

Coating B

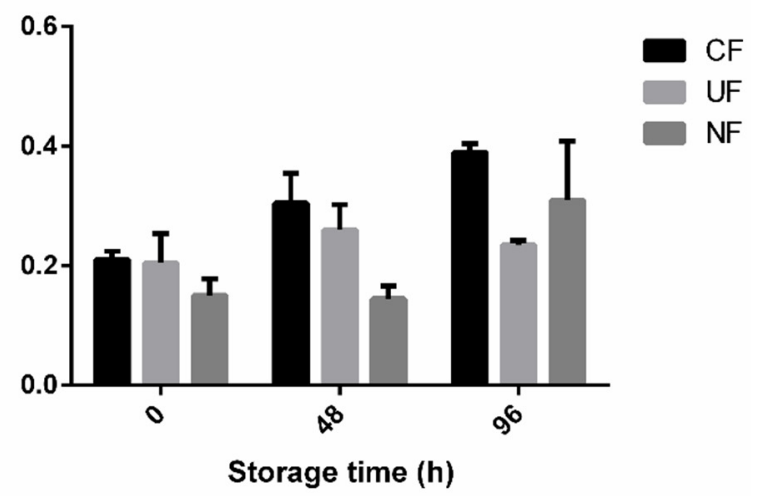

Figure 7. Concentration of thiobarbituric acid reactive substances present in the poultry samples treated with (CF) coated PP film, (UF) uncoated PP film, (NF) no film. Coating A = $5 \mathrm{wt} \%$ P. dioica extract and $7.5 \mathrm{wt} \%$ PVA. Coating $\mathrm{B}=1 \mathrm{wt} \%$ P. dioica extract, $1 \mathrm{wt} \%$ PVA, and $17 \mathrm{wt} \%$ gelatine. Results presented as the average of three samples $(n=3)$. No statistical differences were detected in the pool of tested samples. 
While this set of results seems to point to a lack of antioxidant potential of the enriched coatings, they in turn reinforce the evidence of a slowdown in microbial degradation. Considering the results of the TBARS assay, oxidative degradation does not seem to have occurred to a significant extent, even in the unprotected control samples (NF). This leads to the likely possibility that the colour changes verified using the Chroma meter are due to microbial development. Colour changes due to microbial degradation of the heme pigment are well reported, and several spoilage bacteria, such as Pseudomonas fluorescens and Shewanella putrefaciens, produce recognizable yellow or iridescent pigments easily detectable as colour deviations. [44,45]

\subsubsection{Sensory Analysis}

The results from sensory analysis, presented in Table 1 , show a significant difference $(\alpha=0.001)$ between raw poultry samples treated with the electrospun coating and the untreated samples. A much less pronounced difference ( $\alpha=0.1)$ was observed between samples wrapped in coated film, and those stored in uncoated PP film. The question of whether the subjects considered the sample edible or not also favoured the coated films, with a $66.7 \%$ approval rating, followed by the uncoated films with $35 \%$. The noncoated samples only received a positive appreciation $6.5 \%$ of the times. These differences perceived by the test subjects accurately reflect the microbiological counts and further reaffirm the existence of antimicrobial activity in the PP films coated with formulation B.

Table 1. Number of correct distinctions between samples and conformity ratings provided by the sensory analysis panellists upon four days of sample storage. Distinctions marked with * and ** are different between themselves with a significance level of 0.1 and 0.001 , respectively.

\begin{tabular}{ccccc}
\hline \multirow{2}{*}{ Sample ID } & \multicolumn{3}{c}{ Correct Distinctions } & \multirow{2}{*}{ Conformity (\% approval) } \\
\cline { 2 - 4 } & CF & UF & NF & \\
\hline CF & N/A & $7^{*}$ & $11^{* *}$ & 66.7 \\
UF & $7^{*}$ & N/A & 5 & 35 \\
NF & $11^{* *}$ & 5 & N/A & 6.4 \\
\hline
\end{tabular}

\section{Conclusions}

In this study, the homogenous coatings of electrospun and electrosprayed P. dioica-porphyran-rich extract were applied to poultry products and successfully enhanced shelf-life parameters, including reduced microbial counts, enhanced colour stability, and sensory parameters. Though both nanofibers and nanoparticles were produced, the former had significantly better shelf-life enhancing potential, with greater inhibition of microbial growth compared to uncoated control samples. SEM examination of the coatings revealed that the addition of seaweed extract had a noticeable impact on their microscopic structure, increasing particle/fiber density. Further testing of physical features should now be made to determine the full extent of this difference, and how it can condition the use of these coatings. The full scope and mechanisms of microbial inhibition verified in this study is yet to be fully understood and should also be the focus of future work with these coatings.

Supplementary Materials: The following are available online at http://www.mdpi.com/2079-6412/10/4/315/s1, Figure S1: Full ATR-FTIR spectrum of the solid porphyran-enriched extract

Author Contributions: Conceptualization, R.G., S.M., A.S.-S., A.M. and S.B.; methodology, J.R., P.A., S.F.C.G., J.R.D. and M.A.; project adminstration, R.G., S.M., A.S.-S., A.M. and S.B.; resources, A.S.-S., A.M., N.A. and S.B.; supervision, P.A., J.R.D., R.G., S.M. F.V. A.S.-S., A.M., N.A. and S.B.; validation, P.A., F.V. and A.S.-S.; writing-original draft preparation, J.R.; writing-review and editing, P.A., S.F.C.G., J.R.D., M.A. A.S.-S. and S.B. All authors have read and agreed to the published version of the manuscript.

Funding: This work was supported by the research project "i.FILM - Multifunctional Films for Intelligent and Active Applications" ( ${ }^{\circ}$ 17921) cofounded by European Regional Development Fund (FEDER) through the Competitiveness and Internationalization Operational Program under the "Portugal 2020" Program, Call no. 33/SI/2015, Co-Promotion Projects and by the Integrated Programme of SR\&TD "Smart Valorization of Endogenous Marine Biological Resources Under a Changing Climate" (reference Centro-01-0145-FEDER-000018), co-funded 
by Centro 2020 program, Portugal 2020, European Union, through the European Regional Development Fund. This work was also supported by the Fundação para a Ciência e a Tecnologia (FCT) and Centro2020 through the following Projects: UIDB/04044/2020, UIDP/04044/2020, PAMI - ROTEIRO/0328/2013 (No 022158) and MATIS (CENTRO-01-0145-FEDER-000014 - 3362). João Reboleira, Sara Guerreiro and Mariana Andrade are grateful for their research grant (2016/iFILM/BM) in the frame of iFILM project. Also, this study had the support of Fundação para a Ciência e Tecnologia (FCT), through the strategic project UID/MAR/04292/2019 granted to MARE.

Conflicts of Interest: The authors declare no conflict of interest.

\section{References}

1. Lin, M.; Al-Holy, M.; Mousavi-Hesary, M.; Al-Qadiri, H.; Cavinato, A.G.; Rasco, B.A. Rapid and quantitative detection of the microbial spoilage in chicken meat by diffuse reflectance spectroscopy $(600-1100 \mathrm{~nm})$. Lett. Appl. Microbiol. 2004, 39, 148-155. [CrossRef]

2. Bolumar, T.; Andersen, M.L.; Orlien, V. Antioxidant active packaging for chicken meat processed by high pressure treatment. Food Chem. 2011, 129, 1406-1412. [CrossRef]

3. Jiménez, S.M.; Salsi, M.S.; Tiburzi, M.C.; Rafaghelli, R.C.; Tessi, M.A.; Coutaz, V.R. Spoilage microflora in fresh chicken breast stored at $4{ }^{\circ} \mathrm{C}$ : Influence of packaging methods. J. Appl. Microbiol. 1997, 83, $613-618$. [CrossRef] [PubMed]

4. Narasimha Rao, D.; Sachindra, N.M. Modified atmosphere and vacuum packaging of meat and poultry products. Food Rev. Int. 2002, 18, 263-293. [CrossRef]

5. Schumann, B.; Schmid, M. Packaging concepts for fresh and processed meat - Recent progresses. Innov. Food Sci. Emerg. Technol. 2018, 47, 88-100. [CrossRef]

6. Restuccia, D.; Spizzirri, U.G.; Parisi, O.I.; Cirillo, G.; Curcio, M.; Iemma, F.; Puoci, F.; Vinci, G.; Picci, N. New EU regulation aspects and global market of active and intelligent packaging for food industry applications. Food Control 2010, 21, 1425-1435. [CrossRef]

7. Sanches-Silva, A.; Costa, D.; Albuquerque, T.G.; Buonocore, G.G.; Ramos, F.; Castilho, M.C.; Machado, A.V.; Costa, H.S. Trends in the use of natural antioxidants in active food packaging: A review. Food Addit. Contam. Part A Chem. Anal. Control. Expo. Risk Assess. 2014, 31, 374-395. [CrossRef]

8. Kanmani, P.; Rhim, J.W. Development and characterization of carrageenan/grapefruit seed extract composite films for active packaging. Int. J. Biol. Macromol. 2014, 68, 258-266. [CrossRef]

9. Radusin, T.; Torres-Giner, S.; Stupar, A.; Ristic, I.; Miletic, A.; Novakovic, A.; Lagaron, J.M. Preparation, characterization and antimicrobial properties of electrospun polylactide films containing Allium ursinum L. extract. Food Packag. Shelf Life 2019, 21, 100357. [CrossRef]

10. Fernández-Pan, I.; Carrión-Granda, X.; Maté, J.I. Antimicrobial efficiency of edible coatings on the preservation of chicken breast fillets. Food Control 2014, 36, 69-75. [CrossRef]

11. Lin, L.; Zhu, Y.; Li, C.; Liu, L.; Surendhiran, D.; Cui, H. Antibacterial activity of PEO nanofibers incorporating polysaccharide from dandelion and its derivative. Carbohydr. Polym. 2018, 198, 225-232. [CrossRef] [PubMed]

12. Surendhiran, D.; Cui, H.; Lin, L. Encapsulation of Phlorotannin in Alginate/PEO blended nanofibers to preserve chicken meat from Salmonella contaminations. Food Packag. Shelf Life 2019, 21, 100346. [CrossRef]

13. Salmieri, S.; Lacroix, M. Physicochemical properties of alginate/polycaprolactone-based films containing essential oils. J. Agric. Food Chem. 2006, 54, 10205-10214. [CrossRef] [PubMed]

14. Rojas-Graü, M.A.; Raybaudi-Massilia, R.M.; Soliva-Fortuny, R.C.; Avena-Bustillos, R.J.; McHugh, T.H.; Martín-Belloso, O. Apple puree-alginate edible coating as carrier of antimicrobial agents to prolong shelf-life of fresh-cut apples. Postharvest Biol. Technol. 2007, 45, 254-264. [CrossRef]

15. Abdul Khalil, H.P.S.; Saurabh, C.K.; Tye, Y.Y.; Lai, T.K.; Easa, A.M.; Rosamah, E.; Fazita, M.R.N.; Syakir, M.I.; Adnan, A.S.; Fizree, H.M.; et al. Seaweed based sustainable films and composites for food and pharmaceutical applications: A review. Renew. Sustain. Energy Rev. 2017, 77, 353-362. [CrossRef]

16. Negi, P.S. Plant extracts for the control of bacterial growth: Efficacy, stability and safety issues for food application. Int. J. Food Microbiol. 2012, 156, 7-17. [CrossRef]

17. Yang, C.; Chowdhury, M.A.; Huo, Y.; Gong, J. Phytogenic Compounds as Alternatives to In-Feed Antibiotics: Potentials and Challenges in Application. Pathogens 2015, 4, 137-156. [CrossRef]

18. Pereira, R.; Sousa-Pinto, I.; Yarish, C. Field and culture studies of the life history of Porphyra dioica (Bangiales, Rhodophyta) from Portugal. Phycologia 2004, 43, 756-767. [CrossRef] 
19. Anderson, N.S.; Rees, D.A. 1104. Porphyran: A polysaccharide with a masked repeating structure. J. Chem. Soc. 1965, 5880-5887. [CrossRef]

20. Correc, G.; Hehemann, J.H.; Czjzek, M.; Helbert, W. Structural analysis of the degradation products of porphyran digested by Zobellia galactanivorans $\beta$-porphyranase A. Carbohydr. Polym. 2011, 83, 277-283. [CrossRef]

21. Zhang, Q.; Qi, H.; Zhao, T.; Deslandes, E.; Ismaeli, N.M.; Molloy, F.; Critchley, A.T. Chemical characteristics of a polysaccharide from Porphyra capensis (Rhodophyta). Carbohydr. Res. 2005, 340, 2447-2450. [CrossRef] [PubMed]

22. Isaka, S.; Cho, K.; Nakazono, S.; Abu, R.; Ueno, M.; Kim, D.; Oda, T. Antioxidant and anti-inflammatory activities of porphyran isolated from discolored nori (Porphyra yezoensis). Int. J. Biol. Macromol. 2015, 74, 68-75. [CrossRef] [PubMed]

23. Zhang, Q.; Li, N.; Zhou, G.; Lu, X.; Xu, Z.; Li, Z. In vivo antioxidant activity of polysaccharide fraction from Porphyra haitanesis (Rhodephyta) in aging mice. Pharmacol. Res. 2003, 48, 151-155. [CrossRef]

24. Bhatia, S.; Sharma, K.; Nagpal, K.; Bera, T. Investigation of the factors influencing the molecular weight of porphyran and its associated antifungal activity. Bioact. Carbohydr. Diet. Fibre 2015, 5, 153-168. [CrossRef]

25. Krichen, F.; Karoud, W.; Sila, A.; Abdelmalek, B.E.; Ghorbel, R.; Ellouz-Chaabouni, S.; Bougatef, A. Extraction, characterization and antimicrobial activity of sulfated polysaccharides from fish skins. Int. J. Biol. Macromol. 2015, 75, 283-289. [CrossRef]

26. Jridi, M.; Nasri, R.; Marzougui, Z.; Abdelhedi, O.; Hamdi, M.; Nasri, M. Characterization and assessment of antioxidant and antibacterial activities of sulfated polysaccharides extracted from cuttlefish skin and muscle. Int. J. Biol. Macromol. 2019, 123, 1221-1228. [CrossRef]

27. Greiner, A.; Wendroff, J.H. Electrospinning: A Fascinating Method for the Preparation of Ultrathin Fibers. Angew. Chem. Int. Ed. 2007, 46, 5670-5703. [CrossRef]

28. Anu Bhushani, J.; Anandharamakrishnan, C. Electrospinning and electrospraying techniques: Potential food based applications. Trends Food Sci. Technol. 2014, 38, 21-33. [CrossRef]

29. Ognibene, G.; Cristaldi, D.A.; Fiorenza, R.; Blanco, I.; Cicala, G.; Scirè, S.; Fragalà, M.E. Photoactivity of hierarchically nanostructured ZnO-PES fibre mats for water treatments. RSC Adv. 2016, 6, 42778-42785. [CrossRef]

30. Li, D.; Xia, Y. Electrospinning of nanofibers: Reinventing the wheel? Adv. Mater. 2004, 16, 1151-1170. [CrossRef]

31. Abd El-aziz, A.M.; El-Maghraby, A.; Taha, N.A. Comparison between polyvinyl alcohol (PVA) nanofiber and polyvinyl alcohol (PVA) nanofiber/hydroxyapatite (HA) for removal of Zn2+ ions from wastewater. Arab. J. Chem. 2017, 10, 1052-1060. [CrossRef]

32. Yeum, J.H.; Yang, S.B.; Sabina, Y. Fabrication of Highly Aligned Poly(Vinyl Alcohol) Nanofibers and its Yarn by Electrospinning. In Electrospinning-Material, Techniques, and Biomedical Applications; InTech: London, UK, 2016.

33. Linh, N.T.B.; Min, Y.K.; Song, H.Y.; Lee, B.T. Fabrication of polyvinyl alcohol/gelatin nanofiber composites and evaluation of their material properties. J. Biomed. Mater. Res. Part B Appl. Biomater. 2010, 95, 184-191. [CrossRef]

34. Cui, H.; Bai, M.; Rashed, M.M.A.; Lin, L. The antibacterial activity of clove oil/chitosan nanoparticles embedded gelatin nanofibers against Escherichia coli O157:H7 biofilms on cucumber. Int. J. Food Microbiol. 2018, 266, 69-78. [CrossRef] [PubMed]

35. Jaworek, A.; Sobczyk, A.T.; Krupa, A. Electrospray application to powder production and surface coating. J. Aerosol Sci. 2018, 125, 57-92. [CrossRef]

36. Wang, J.; Jansen, J.A.; Yang, F. Electrospraying: Possibilities and challenges of engineering carriers for biomedical applications-A mini review. Front. Chem. 2019, 7, 258. [CrossRef] [PubMed]

37. Alehosseini, A.; Gómez-Mascaraque, L.G.; Ghorani, B.; López-Rubio, A. Stabilization of a saffron extract through its encapsulation within electrospun/electrosprayed zein structures. LWT 2019, 113, 108280. [CrossRef]

38. Kim, M.K.; Lee, J.Y.; Oh, H.; Song, D.W.; Kwak, H.W.; Yun, H.; Um, I.C.; Park, Y.H.; Lee, K.H. Effect of shear viscosity on the preparation of sphere-like silk fibroin microparticles by electrospraying. Int. J. Biol. Macromol. 2015, 79, 988-995. [CrossRef] 
39. He, D.; Wu, S.; Yan, L.; Zuo, J.; Cheng, Y.; Wang, H.; Liu, J.; Zhang, X.; Wu, M.; Choi, J.; et al. Antitumor bioactivity of porphyran extracted from Pyropia yezoensis Chonsoo2 on human cancer cell lines. J. Sci. Food Agric. 2019, 99, 6722-6730. [CrossRef]

40. Noseda, M.D.; Viana, A.G.; Duarte, M.E.R.; Cerezo, A.S. Alkali modification of carrageenans. Part IV. Porphyrans as model compounds. Carbohydr. Polym. 2000, 42, 301-305. [CrossRef]

41. Matsuhiro, B.; Rivas, P. Second-derivative Fourier transform infrared spectra of seaweed galactans. J. Appl. Phycol. 1993, 5, 45-51. [CrossRef]

42. Wang, P.; Zhao, X.; Lv, Y.; Li, M.; Liu, X.; Li, G.; Yu, G. Structural and compositional characteristics of hybrid carrageenans from red algae Chondracanthus chamissoi. Carbohydr. Polym. 2012, 89, 914-919. [CrossRef] [PubMed]

43. Civille, G.V.; Carr, B.T.; Meilgaard, M. Sensory Evaluation Techniques, 4th ed.; CRC Press: Boca Raton, FL, USA, 2015; ISBN 9781482216905.

44. Ercolini, D.; Russo, F.; Torrieri, E.; Masi, P.; Villani, F. Changes in the spoilage-related microbiota of beef during refrigerated storage under different packaging conditions. Appl. Environ. Microbiol. 2006, 72, 4663-4671. [CrossRef] [PubMed]

45. Barnes, E.M.; Thornley, M.J. The spoilage flora of eviscerated chickens stored at different temperatures. Int. J. Food Sci. Technol. 1966, 1, 113-119. [CrossRef]

(C) 2020 by the authors. Licensee MDPI, Basel, Switzerland. This article is an open access article distributed under the terms and conditions of the Creative Commons Attribution (CC BY) license (http://creativecommons.org/licenses/by/4.0/). 